\title{
Makrokosmos I
}

\author{
Roomet Jakapi, Enn Kasak
}

\begin{abstract}
Teesid
Me keskendume sellele osale makrokosmosest, mida päriskosmoses ei ole ja mis omab mõtet koos inimesega, nt taevas ja põrgu. Peamiselt käsitleme Briti uusaegset mõtlemist tänapäevase teaduse alguse perioodist (1650-1750). Uusaegses mõtlemises on palju keskajast pärinevat ja mõneti on see isegi olulisem, kui teaduslik mõtlemine, mis alles hakkab tekkima. Makrokosmiliste ja teoloogiliste arutelude juures kasutati tollal sageli täppisteaduslikku meetodit. Loodeti, et inimese mõistus on võimeline välja selgitama asjade olemuse, nii nagu Johannes Kepler oli võimeline välja rehkendama planeetide asukoha.
\end{abstract}

Märksõnad: hinge rännakud, põrgu, makrokosmos, taevas, teaduse ajalugu, uusaja filosoofia.

Enn Kasak: Makrokosmos on klassikaline termin. Eristatakse mikrokosmost ja makrokosmost, kusjuures sõnastikud eristavad tänapäevalgi mikrokosmost kui väikest maailmakorda ehk inimest ja makrokosmost kui suurt maailmakorda ehk kosmost. Esimesel pilgul tundub kõik selge olevat, kuid võib küsida kaht asja. Esiteks, n-ö tänapäeva inimese seisukohalt, et miks neid koos käsitletakse, ja teiseks, mis vahe on kosmosel ja makrokosmosel. Esimesele küsimusele on võib-olla kergem vastata. Tegemist on ajaloolise kontekstiga. Pikkade aegade jooksul, juba antiigi lõpul ning kogu keskaja vältel on käsitletud inimest ja kosmost kui teatud analoogiat, õigemini nendele on omistatud teatud analoogia. Mõned näited: inimese verele vastab makrokosmilises mõttes ookean, inimese luudele vastavad kivid jne. See väga huvitav teema aga jääb meie praeguse vaatluse alt välja.

Seega on makrokosmos päris kosmos ja veel midagi. Mis võiks see veel midagi olla?

Päriskosmos on nt planeedid, tähed ja komeedid. Mida enamat on siis veel makrokosmoses? Kui kujutame ette, et makrokosmos on inimlik vaatepunkt kosmosele, siis peab selles olema kõik, mis on inimesele tarvilik. Teiste sõnadega, sinna kuuluvad ka näiteks taevas ja põrgu. On ju selge, et need ei asu minu korteris ega kusagil alakorrusel, vaid asuvad kusagil kosmoses. Olgu nad siinpoolsuses või sealpoolsuses, aga kusagil nad peavad asuma. Ja päriskosmoses ei taha nad ka hästi asuda, sellepärast et nad on inimese-

http://haldjas.folklore.eeltagused/nr25/kosmos.pdf 
kesksed objektid. Kui vaadata tänapäeva inimese pilguga, siis eks inimene ole ju mingisugune hallitus kusagil väikese planeedi pinnal ning selles mõttes ei kuulu taevas ja põrgu kui täiesti inimlikud, inimesega seotud objektid päriskosmosesse. Keskendudes makrokosmosele vaatleme seda osa makrokosmosest, mida päriskosmoses ei ole. Päriskosmosest räägime üksnes niipalju, kui see seondub käsitletava alaga. Teiste sõnadega: räägime taevast, põrgust ja sellest kosmose osast, mis seondub otseselt inimesega.

Ma ei taha öelda, et see on kosmos inimese vaatepunktist, aga võib-olla on parem öelda, et see on kosmos inimese jaoks, see osa kosmosest, mis omab mõtet koos inimesega.

Makrokosmosega tegeldi juba antiigi lõpul ja keskajal. Aga ka selle tahaksime jätta vähemalt esialgu käsitlusest kõrvale. Tahaksime siduda makrokosmose probleemi tänapäevaste probleemidega ja parim võimalus selleks on minna perioodi, kus tekkisid tänapäevase teaduse alged, kus pandi alus tänapäevasele teadusele.

Kui vaatame tänapäevast teadushoonet ja märkame seintes näiteks pragusid - kusagil midagi vajub, kusagil midagi kerkib - , siis tavaliselt küsib arhitekt või asjatundja kohe: aga kuidas on lood vundamendiga, millal see rajati?

Roomet Jakapi: Oleme seadnud oma teema ajalisteks piirideks selle perioodi, mida võib käsitleda (uusaegses mõttes) loodusteaduse väljakujunemise perioodina, mis seostub enam-vähem ajavahemikuga 1650-1750. Geograafiliselt oleme keskendunud Inglismaale ehk laiemalt Briti saartele. Seda sellepärast, et brittidel on erakordselt tähtis osa uusaegse teaduse väljakujunemisel, alates Isaac Newtonist, Robert Boyle'ist ja teistest suurkujudest. Selle perioodi tekste lugedes on mind hämmastanud paljud asjad. See maailm, milles need inimesed, kaasa arvatud teaduse suurkujud, elasid, see mõttemaailm ja nende maailmapilt on, nagu Enn Kasak ennist ütles, vundamendiks või raamiks sellele, kus me praegu elame, selles mõttes on meil nendega suur ühisosa. Teisest küljest on nende mõttemaailm meie omast hämmastavalt, mõnikord šokeerivalt erinev.

Enn Kasak: Arutame neid asju nüüd natuke lähemalt, muidu jääb meie jutt liiga üldiseks. Mis võis olla tolleaegsete inimeste mõttemaailmas olulisel kohal olla? Ütleme, et seal oli kõigepealt usk materiaalse maailma olemasolusse. 


\section{Roomet Jakapi: Kindlasti.}

Enn Kasak: Mis siis veel? Kuidas oli suhe teadusega? Teadus oli vist juba autoriteet, nagu tänapäevalgi. Tänapäeva inimesele on teadus ainuke usaldatav teadmiste saamise viis. Mõningate lugejate rõõmuks võime öelda: võib-olla on olemas veel mõned teadusesarnased distsipliinid, mis tõe avavad. Kas uusajal oli teadus autoriteet?

Roomet Jakapi: Tollasele inimesele oli vähemasti üks väga oluline autoriteet teaduse kõrval, pigem koguni esmane autoriteet Piibel. Ikka veel.

Enn Kasak: Kusjuures tuleb täpsustada, et jälle oli autoriteet Piibel, sest vahepeal, keskajal, oli ajastu, kus lihtinimest ei lastudki Piibli ligi, nii et mõnes mõttes oli taas saabunud aeg, kus mõtleja sai ise Piiblit lugeda. Ja Piiblit lugedes tekkis tal lootus leida sealt üles olulisi tõdesid, mis olid vahepeal mattunud skolastiliste arutluste kultuurikihi alla.

Roomet Jakapi: Seda küll. Kuigi täpsustagem, et eelkõige peame silmas inimkonna helgemates peades toimuvat.

Enn Kasak: Jah, mõtlejaid oli varemgi. Kui neil oli vastav haridus ja kuuluvus, said nad küll Piiblit lugeda, kuid varem polnud kombeks diskuteerida asjade üle, mida see sisaldas, ning seda väga mitmel põhjusel. Spetsiaalse ettevalmistuseta mõtleja diskuteerimisvabadus Piibli üle tekkis ikkagi uusaja alguses.

Roomet Jakapi: Selle jutu jätkuks võiks proovida välja tuua mõned olulised erinevused nende ja meie kõige üldisemas maailma mõistmises. Esimene asi, mis silma torkab, on see, et tollaste mõtlejate, sealhulgas uusaja teaduse loojate arvates ei olnud maailm vanem kui kuus või seitse tuhat aastat. See on midagi põhimõtteliselt erinevat sellest, mida teame tänapäeval, mil maailma vanust rehkendatakse miljardite aastatega.

Enn Kasak: Ja isegi rohkem. Maailma vanuseks arvatakse kuni 15 miljardit aastat. Kui Mark Twain ütles 19. sajandi lõpul oma raamatus Kirjad Maa pealt maailma vanuseks sada miljonit aastat, siis oli see tollal enesestmõistetav. M. Twain viskas nalja, võrreldes maailma vanust Eiffeli torni kõrgusega. Kuna inimkonna va- 
nus on sel juhul võrreldav värvikihi paksusega torni tipus, on selge, et Eiffeli torn on ehitatud just selle värvikihi jaoks. Ent niiviisi saab ironiseerida vaid inimene, kes kujutab ette, et maailm on juba sadu miljoneid aastaid vana. Meid huvitaval perioodil aga usuti, et maailm on kuus-seitse tuhat aastat vana ja ka seda peeti kohutavalt kõrgeks vanuseks. Mõelge ise, Friedrich Reinhold Kreutzwald elas 200 aastat tagasi, see oli kohutavalt ammu. Lehola Lembitu elas 800 aastat tagasi, sellega võrreldes pole 5000 aastat mitte just vähe.

Roomet Jakapi: See on tohutult palju, tohutult. Ja veel võime kohe ütelda, et nendele (mulle meeldib vastandada nemad ja meie) oli maailm korraga valmis tehtud, selle tekkimine ei olnud mingisugune miljonite ja miljardite aastate pikkune protsess. Hea küll, maailm loodi kuue päevaga, aga põhimõtteliselt oli see ikkagi korraga valmis tehtud. Tähed olid üles riputatud, planeedid olid pandud orbiite mööda käima, kusjuures äkitselt oli selgunud, et neid liikumisi saab väga täpselt välja rehkendada. Mis kõik viitab sellele, et asja pidi kokku panema lõputult tark mõistus.

Enn Kasak: Tahan rõhutada, et usk väljarehkendamise jõudu oli kaunis värskelt tekkinud umbes tollelsamal ajastul ja seda tänu Johannes Keplerile, kes suutis leida meetodi planeetide liikumise kirjeldamiseks minutite täpsusega. Kuni tolle ajani nägid astronoomid-astroloogid vaeva, et planeetide seise välja arvutada ning eksisid parimal juhul nädalaid, väga heal juhul ja lühikese perioodi korral võib-olla päevi. Ja nüüd äkitselt selgus, et selles keerukas ja vanas ülesandes, mida aastatuhandeid ei olnud suudetud korralikult lahendada, oli inimene võimeline saama väga täpseid tulemusi. Selline usk inimesse iseloomustab tolleaegset mõtlejat ja on mõnes mõttes sarnane tänapäeva inimese uskumustele. Tänapäeva inimesel on tunne, et oleme nüüd hakanud maailmast õigesti aru saama, meie esivanemad ei taibanud ikka suurt midagi. Kuigi teadlased rääkisid juba sada aastat tagasi galaktikast, võib-olla küll ka tähtedest, siis nüüd teame, et on olnud Suur Pauk ja et maailmal on olnud just sellega seotud algus. Saabunud on hoopis uus, enneolematu ajastu.

Sama tunne oli tolle aja inimesel. Ta oli äkitselt aru saanud, et inimene on võimeline välja rehkendama seda, mis maailmas toi- 
mub - seega on saabunud täiesti uus ajastu. See on kindlasti analoogia tänapäevase ja tollase mõtleja arusaamades.

Ja on veel teine moment, see puudutab seda, kuidas me tolle aja inimestest räägime, näiteks Isaac Newtonist. Tänapäeval on kombeks näidata teda pühakuna, kes sõnastas tähtsalt ja targalt oma kuulsad seadused, aga muidu oli ta tõenäoliselt vaba kõikvõimalikest pattudest n-ö teaduslikkuse suhtes. Asja lähemalt vaadates see nii ei ole, kuid see ei olnud probleem tolle ajastu kontekstis.

Märkasin hiljaaegu, et Eesti ajakirjandusest jooksis läbi tohutu avastus, et I. Newton on tegelnud ka mitteteaduslike tõehankimisviisidega. Selliseid näiteid on kerge leida, tuleb vaid sirvida teadusloolisi tekste. Näiteks Platoni kosmoloogiast rääkides pajatatakse õpikutes, et seal on planeetide sfäärid, mis liiguvad, kinnistähtede sfäär jne. Platonit lugedes leiame hoopis midagi muud: $J a$ ta [demiurgos] vabastas maailma sihitust ringiuitamisest - s.t pani pöörlema, aga mitte edasi-tagasi liikuma - ja tal [maailmal] ei olnud silmi, sest väljas pole midagi vaadata... Me õpime tänapäeval Platoni tekste tundma tugevasti tsenseerituna, neist on välja puhastatud see, mida tänapäeval ei peeta teaduslikuks.

Uusaja teadlaste puhul peame arvestama, et see osa, millest tänapäeval on kombeks vaikida, on olnud sama oluline või veelgi olulisem sellest, mida tänapäeval oluliseks peetakse.

Roomet Jakapi: Püüamegi pöörata tähelepanu eelkõige tumedaks jäänud regioonidele, mida täna ei taheta näha.

Enn Kasak: Eks ole koolis Newtoni seadustest juba piisavalt räägitud, miks me peaksime neid siin üle rääkima. Tema muud harrastused on ehk märksa põnevamad.

Roomet Jakapi: Uusaegne teadlane tegutses nõnda, et tal oli ühes käes teleskoop ja teises Piibel. Arvan, et see on üsna tabav kujutlus.

Enn Kasak: Aga äkki tuleneb see sellest, et neil ei olnud veel piisavalt teadmisi. Nad mõtlesid nagu tänapäeva inimene, aga lihtsalt olid veel lollikesed, ei tundnud isegi evolutsiooniteooriat...

Roomet Jakapi: Et põhimõtteliselt olid nad samasugused nagu meie, aga veidi tobud? 
Enn Kasak: Evolutsiooni kohta olen kuulnud väidet, et juba Vanas Kreekas pakkus Empedokles välja evolutsiooni idee. Seda võiks tõrjuda näitega tänapäevast: loeme mitmesugust kirjandust ja võime sealt leida igasuguseid huvitavaid ideid. Seda, kuidas ufonaudid tulevad ja lähevad, kuidas on dimensioonid sinna-tänna, kuidas saab vaimselt rännata jpm. Võib-olla kümne tuhande aasta pärast oskab keegi öelda, et näed, juba neil olid olemas kõik need ideed, mille abil korraldada tähtedevahelist rändamist. Aga... meil pole sellest mingit kasu, sest me ei suuda eristada toimivat ideed jamast. Selles mõttes võisid evolutsiooniideed ju hõljuda kusagil teiste ideede vahel, aga tegelikult ei olnud tolle aja inimese jaoks evolutsiooni olemas.

Roomet Jakapi: Nüüd oleme välja toonud mõned selle ajastu mõtlemisele iseloomulikud punktid. Esiteks, universumi vanuseks arvati mõni tuhat aastat, mis tundub tänapäeva teaduslikust seisukohast naeruväärne, ja teiseks, et see kõik arvati olevat korraga valmis tehtud. Ka peab arvestama, et tolle ajastu mõtlemise kontekstis ei saanud olla juttugi bioevolutsioonist. Ahvi, ka inimahvi ei peetud meile lähedasemaks sugulaseks kui mis tahes muud looma, sest inimest eristas kõikidest teistest loodud olenditest vähemalt kaks väga olulist asja. Esiteks oli inimesele antud mõistus, mida loomal ei ole. Mitte ühelegi loomale - ei ahvile, delfiinile ega kilpkonnale - ole antud niisugust mõistuse valgust, mille abil inimene võib avastada suurepäraseid tõdesid maailma kohta. (Ja ühtlasi on inimesel keel, mida ta kõneleb, seda loomadel ei ole, neil on ainult häälitsused.) Ja teiseks, mis on ilmselt veelgi olulisem, kuid kipub unustusse vajuma, on see, et tollase inimese arvates eristas inimest kõikidest teistest olenditest see, et talle oli lubatud igavest elu.

Enn Kasak: Siin peaks vist täpsustama, sest lihtne on öelda: tollal usuti, et inimesel on surematu hing. Peaks ütlema, miks on vaja kasutada terminit igavene elu.

Roomet Jakapi: Kõige täpsem oleks tõesti öelda, et inimesele oli lubatud igavest elu, sellepärast et ei ole sugugi selge, mis hingest saab tollaste arvamuste ja teooriate seisukohalt rääkida. Neid teooriaid ja seisukohti oli üsna palju. See ei ole nii lihtne, et inimene sureb, maetakse maha ja hing jääb kusagile virelema, ja nii jääbki, või jõuab paradiisi. Kõik oli palju komplitseeritum, see on midagi 
niisugust, mida mulle meeldib nimetada hinge ja keha rännakuteks universumis. Tolle perioodi tekste lugedes on mind tõesti alati hämmastanud ja vaimustanud nende arutelude üksikasjalisus ja mingis mõttes teaduslikkus, või vähemasti filosoofilisus, ja intellektuaalne kirg, millega on püütud ka surmajärgse elu küsimusi käsitleda ja lahendada.

Enn Kasak: Aga see on ju iseenesestmõistetav. Kujutage ette, et tahame minna automatkale võõrale maale. Kas me ei ürita siis hankida enne raskele matkale asumist kaarti. Ilmselt üritame. Võib ette kujutada, et tolleaegne inimene oli oma maapealse elu kaardi üldjoontes paika sättinud, aga teda häiris vältimatult saabuv surm ja ta tahtis teada, mis laadi rännak teda ees ootab, ning ta rakendas info hankimiseks kogu oma intellektuaalse jõu. Kusjuures väga põnev on see, et sellise analüüsi elemente kohtame juba keskaja filosoofias. Juba Augustinus võttis enesestmõistetavana mõningaid tõdesid, millest inimene ei peagi aru saama, ja samal ajal üritas meeleheitlikult seletada, kuidas on võimalik, et keha on põrgus, kuid ei põle tules ära. Tehti meeleheitlikke jõupingutusi mingi detaili seletamiseks, samal ajal, kui probleem võeti lambist või laest.

Roomet Jakapi: Uusaegsetele aruteludele on väga iseloomulik, et ühest küljest mööndi, et on teatud hulk tõdesid, mida peeti mõistuseülesteks, niisugusteks, milleni inimene ise oma mõistuse valgusega iial ei jõua. Need on talle antud, ilmutatud. Ja sealjuures on nad niisugused, et neist ei ole võimalik õigesti aru saada. Mingil määral aga mööndi, et tegemist on müsteeriumiga, saladustega. Me lihtsalt ei tea, mis täpselt juhtub siis, kui saabub maailma lõpp. Samas on täheldatav, kuidas loodusteaduste tekke perioodil mindi nendesamade teoloogiliste nüansside ja probleemide kallale loodusteadusliku aparatuuriga. Püüti neid küsimusi lahata, ja ma kinnitan teile juba ette, et need lahendused, mida pakuti välja näiteks seoses surnute ülestõusmisega, kombineerides seda füüsika või keemiaga, oli juba iseenesest müsteerium, mis ületab meie mõistuse vastuvõtuvõime.

Enn Kasak: Aga siinkohal oleks ehk vaja ikkagi arutleda teaduse ja religiooni seotuse üle. Väga sagedase hoiaku järgi on see lihtsalt anakronism. Meil oli jutuks väga tähtis seisukoht: kui inimene tollel ajal ei uskunud Jumalat, pidi ta olema loll ja pahatahtlik. 
Roomet Jakapi: Jah, kindlasti mitte lihtsalt hereetik ega mingisugune kahetsusväärne teisitimõtleja. Arusaam oli ikkagi selline, et kuna inimesele on antud mõistuse valgus, siis see tähendab, et kui ta seda rakendab, kui ta seda õigesti rakendab, jõuab ta vältimatult arusaamiseni, et maailm ei saa eksisteerida ega tekkida iseenesest. Sest on selge, et maailm on olemas ja et ta pole igavesti olemas olnud. Ajastu nõudis, et jõutaks tõdemuseni, et selle kõige taga peab olema üks kõigeväeline "superolend", kes on vaim.

Enn Kasak: Kusjuures mitte kõik rahvad ei ole suutnud oma mõistust rakendada, meenutati tollel ajal.

Roomet Jakapi: Just nimelt. Näiteks oma Essees inimmõistusest põhjendas kuulus inglise filosoof John Locke, miks paljudel rahvastel on nii imelikud arusaamised moraalist. Neil on imelikud kombed, näiteks mõned söövad oma lapsi. Tuleb välja, et terved rahvad, suured inimrühmad elavad pimeduses, sellepärast, et nad ei rakenda kunagi oma mõistust õigesti. Kui nad seda teeksid, jõuaksid nad nendesamade tõdedeni nagu eurooplasedki. Tuletaksid sealt teatud moraaliprintsiibid ja elaksid üldse õigesti.

Enn Kasak: Ja jõuaksid loomulikult Jumala ja ainujumala mõisteni.

Roomet Jakapi: Ja ka hinge surematuse tõeni.

Enn Kasak: Kui nad vaevuksid oma mõistust rakendama.

Roomet Jakapi: Aga paljud ei vaevu. See muidugi ei ole üksnes tolle ajastu spetsiifika.

Enn Kasak: On veel üks tahk. Kui inimene läheks väikse lapse juurde ja hakkaks talle seletama, et nagunii ei saa sust asja, nagunii tabab sind elus ebaõnn, nagunii saab sinust varas jne, siis öeldaks selle inimese kohta, et ta on pahatahtlik. Sama näite jätkuks sobib järgmine juhtum. Keegi leiab oma pangaarvelt ootamatult suure summa, miljoneid dollareid, ja seda ilma igasuguste tingimusteta, täieliku õigusega kasutada, lihtsalt see kuulub talle. Saabub advokaat, kes teatab, et teie arvele on kantud teile täieõiguslikult kuuluv summa. Sel juhul hakkavad vist väga vähesed rääkima: “Oi, ma ei taha sellest rahast midagi kuulda, ma tahan palehigis rügada ja ise raha teenida." Aga kui siis tuleb keegi ja küsib: "Kuidas sa ikka võtad 
selle raha vastu? Kuidas on võimalik, et ärkasid hommikul üles ja osutusid rikkaks ega tahagi enam palehigis leiba teenida?" Ilmselt öeldakse ka siis, et rääkija on pahatahtlik olend.

Analoogiliselt oleks pahatahtlik see, kes hakkaks väitma, et inimesel ei olegi erilist kohta universumis, talle ei olegi lubatud igavest elu. Selline hoiak oleks pahatahtlik just sellepärast, et meil on teada mõned tõed, mida me peame õigeks ja mis meile meeldivad. Me ei pea neist loobuma lihtsalt niisama, sellepärast, et mõni pahatahtlik inimene meie kallal norib. Neist loobumiseks peavad olema väga mõjuvad põhjendused.

Ma tahaksin tuua veel kolmandagi võrdluse. Võtame õhus lendava püssikuuli. Temagi võiks ta ette kujutada, et ta lendab vabalt ja tabab täiesti vabalt valitud märklauda. Sest kuul ei taju enam toru, kus ta alguses sees oli, kus teda kiirendati ja kust ta välja sihiti. Sellele on väga sarnane olukord uusaegse mõtlemisega - see on välja sihitud, välja tulistatud sellisest mõtlemisest, kus Jumal on olemas, kus inimesele on lubatud igavene elu ja inimesel on maailmas eriline seisund. Selle lõigu võiks võtta kokku sõnadega: inimene, kes ei usu Jumalat, on loll ja pahatahtlik.

Roomet Jakapi: Vähemalt oli nende arvates.

Enn Kasak: Just nimelt. Loomulikult ma räägin nende arvamusest.

Roomet Jakapi: Muidugi on alati olnud teisitimõtlejaid ja oli ka siis. Neid ja nende arvamusi on omakorda väga huvitav lugeda. Alati oli mingi toimiv, kehtiv doktriin või õpetus, millega vastuollu minna. Seda ei pruukinud muidugi igaüks julgeda, sest see võis tuua kaasa teatavaid repressioone.

Enn Kasak: Teisitimõtlemine oli tõesti ebanormaalne.

Roomet Jakapi: Mõned vältisid probleeme sellega, et avaldasid, nagu tol ajal tavaline, anonüümseid pamflette, selliseid väikesi kirjutisi, kuhu autori nime peale ei pandud ja kus üks isand või mõnikord ka emand avaldas arvamust või vaidles tuliselt mis iganes küsimuses. Tuli ette juhtumeid, kus raamatud, avaldatud teosed, põletati ära. Nii juhtus näiteks John Tolandi, tuntud teisitimõtleja, teosega, kusjuures avaldati arvamust, et õige oleks ta ise ka ära põletada. 
Enn Kasak: Sama probleem avaldus isegi märksa hiljem David Hume'i puhul. Ta arvas, et jumalatõestused pole midagi väärt, kuid ei julgenud neid sõnu enda sõnadeks tunnistada, vaid kirjutas, et need on tema skeptilise sõbra spekulatsioonid, mida tema isiklikult üldse ei jaga. Ilmselt polnud nendel teemadel rääkimine ohutu.

Roomet Jakapi: Nõukogude ajal kirjutati ju ka teatud mõttes samal viisil, siin on märgatav paralleel.

Enn Kasak: Kui võtta arutluse käik kokku, siis rääkisime ja jätkame edaspidigi arutelu makrokosmosest, sellest kosmose osast, mis on inimese jaoks vajalik või mis on olemas tänu inimese olemasolule. Keskendume uusaja Inglismaale, täpsemalt perioodile 1650-1750 ehk teaduse algusperioodile. Tolle ajastu mõtlemine pärineb paljus keskajast, see pärand on mõneti olulisem kui teaduslik mõtlemine, mis alles hakkas tekkima. Tänapäevases kontekstis on kombeks tihti see teine osa ära unustada või tühiseks kuulutada. Makrokosmiliste ja teoloogiliste arutelude juures kasutati tollal teaduslikku meetodit, täppisteaduslikku meetodit, üritati arvutada, üritati loogiliselt tuletada. Oli lootus, et inimese mõistus on võimeline välja selgitama asja olemuse, täpselt nii nagu Johannes Kepler oli võimeline rehkendama välja planeetide asukoha. 